\title{
Effects of age and sex on neurophysiological substrates of empathy: a cross-sectional EEG study
}

Josiane Héroux ${ }^{\mathrm{a}, \S}$, Samuel Guay ${ }^{\mathrm{a}, \mathrm{b}, \S}$, Sven Joubert ${ }^{\mathrm{a}}$, Béatrice P.-De

Koninck $^{\mathrm{a}, \mathrm{b}}$, Virginie L. Blanchette ${ }^{\mathrm{c}}$, Christelle Beaulieu ${ }^{\mathrm{c}}$, and Louis De Beaumont ${ }^{\mathrm{b}, \mathrm{d} *}$

${ }^{a}$ Department of Psychology, University of Montreal, Montreal, Canada; ${ }^{b}$ Research Centre, Hôpital du Sacré-Coeur de Montréal, Montreal, Canada; ${ }^{c}$ Department of Psychology, Université du Québec à Trois-Rivières, Trois-Rivières, Canada;

${ }^{d}$ Department of Surgery, University of Montreal, Montreal, Canada

${ }^{\S}$ Both authors contributed equally to this work.

*Corresponding author:

Louis De Beaumont

Research Centre, Hôpital du Sacré-Coeur de Montréal

5400 Blvd Gouin W,

Montreal, Quebec, Canada

H4J 1 C5

514-338-2222 ext.7722 louis.de.beaumont@umontreal.ca

This work was supported by the Fonds de recherche du Quebec Research Scholar program.

No potential conflict of interest was reported by the authors.

The data that support the findings of this study are available from the corresponding author, L.D.B., upon reasonable request. 


\title{
Effects of age and sex on neurophysiological substrates of empathy: a cross-sectional EEG study
}

\begin{abstract}
Although empathy is an indispensable competence to social adaptation throughout the lifespan, it has been mostly studied with subjective, questionnaire-based measures in the context of healthy aging. Electroencephalography (EEG) provides an objective measure to investigate underlying neurophysiological processes related to empathy through mu rhythm. The current study used empathy-related $\mathrm{mu}$ rhythm during the observation of emotional facial expressions (EFE) in addition to the Empathy Quotient questionnaire in order to explore age-related changes of empathy across sexes. A total of 65 participants, including 33 young adults and 32 seniors, took part in this study. They were instructed to observe as well as to try experiencing emotional facial expressions (joy, fear, neutral) depicted on short video clips during which continuous EEG was recorded. They also completed the Empathy Quotient (EQ) questionnaire. Young adults reacted more strongly to emotional EFEs. Seniors perceived themselves as less empathic and exhibited an equivalent neurophysiological response to emotional and neutral stimuli. A significant sex effect in favour of females was found on mu rhythm modulation. Mu rhythm appears to be an age and sex sensitive neurophysiological marker linked to empathy and could therefore serve as an objective measure of empathy.
\end{abstract}

Keywords: mu rhythm; mu suppression; normal aging; social cognition; emotional facial expression; EFE; electroencephalography

RUNNING HEAD TITLE: A cross-sectional EEG study of empathy 


\section{Introduction}

The considerable scientific interest for empathy witnessed over the past few decades stems from its crucial role in human social adaptation throughout the lifespan (Decety and Svetlova, 2012; Tousignant, Eugene, \& Jackson, 2017). Empathy emerges from a combination of an automatic process allowing one to experiment and share a perceived emotion (emotional empathy) as well as a conscious cognitive (cognitive empathy) effort to understand and imagine one's emotional state (Decety and Jackson, 2004). Deficits in empathy are associated with reduced social functioning (Bailey, Henry, \& Von Hippel, 2008).

As people get older, however, automatic and controlled processes underlying empathy seem to evolve differently, leading to distinct developmental trajectories (Wieck and Kunzmann, 2015). Some studies suggest that cognitive empathy progressively diminishes (Henry, Phillips, Ruffman, \& Bailey, 2013; Moran, 2013; Sun, Luo, Zhang, $\mathrm{Li}, \& \mathrm{Li}, 2018$ ) while emotional empathy seems to remain stable or even improve over time (Sun, et al., 2018; Sze, Gyurak, Goodkind, \& Levenson, 2012; Ze, Thoma, \& Suchan, 2014). Nevertheless, the scientific literature on empathy and normal aging is mostly based on self-reported questionnaires, which cannot easily be exempt from unwanted social desirability bias (Pernigo et al., 2015; van de Mortel, 2008).

In recent years, the social neuroscience community has been interested in developing objective markers of empathy through recordings of brain activity elicited by emotional stimuli (Narme et al., 2010). Since emotional empathy is less studied than cognitive empathy in the aging population, the present study will focus on the emotional dimension of empathy. In its modern conceptualization, the definition of emotional empathy is based on a direct link between perception and action. For the observer, the perception of someone's action or emotion automatically activates the same somatic and neuronal representations as the direct experience (Preston and de Waal, 2002). Indeed, 
the same facial muscles and brain regions underlying its expression would activate spontaneously, facilitating its action recognition and understanding (Hobson and Bishop, 2017). Emotional empathy would therefore result from a mechanism of motor and affective resonance for which imitation would be its principal driving force. However, aging was shown to detrimentally affect the synchronicity of automatic somatic and neuronal responses underlying emotional empathy processes (Chen, Chen, Decety, \& Cheng, 2014; Hühnel, Fölster, Werheid, \& Hess, 2014).

The effects of aging on emotional empathy would be characterized by specific activation patterns, depending on whether it is a peripheral or a central nervous system measure. Electromyography (EMG) recording automatic somatic responses during the observation of emotional facial expressions such as joy, anger and sadness, are comparable through aging (Bailey and Henry, 2009; Hühnel, et al., 2014). These results suggest a preservation of the affective response, as manifested by an intact imitative behavior. Similarly, an increase in physiological indicators during the observation of movies aiming to induce an empathic response, including heart rate and electrodermal responses, in a population aged between 60-80 years suggests enhanced affective empathy among seniors (Sze, et al., 2012). In contrast, data from a recent functional magnetic resonance imaging (fMRI) study suggest a decrease in age-related emotional empathy (Chen, et al., 2014; Riva et al., 2018). In the latter study, authors have suggested that this pattern of results possibly reflects age-related decline of certain cortical regions functionally linked to empathic skill including insular and cingulate cortices. Taken together, emerging interpretations of these study findings might be that the affective response of empathy during normal aging is only reduced at the neuronal level. A possible explanation for these inconsistencies between peripheral and central measures lies in the nature of responses inherent to emotional empathy. To the best of our knowledge, only 
fMRI has been used to characterize the neural basis of empathy among the elderly population (Chen, et al., 2014; Riva, et al., 2018). Yet, other techniques such as electroencephalography (EEG) provide real-time measures of the neuronal response to the presentation of stimuli (Neumann and Westbury, 2011).

EEG objectively and non-invasively quantifies electrical cerebral activity timelocked to stimulus presentation. Emotional facial expressions are often used as stimuli to study socially complex skills, including empathy, as facial expressions powerfully communicate emotions to others in everyday life (Moore, Gorodnitsky, \& Pineda, 2012; Rayson, Bonaiuto, Ferrari, \& Murray, 2016). EEG were shown useful in demonstrating that the mere observation of emotional facial expressions elicits similar brain activation patterns than those involved in their expression (Rayson, et al., 2016). The recorded neuronal activity specific to emotion recognition is thought to emerge from the activation of a particular cell population, commonly referred to as the mirror neuron system (MNS), that is believed to play a crucial role in understanding of action (Hobson and Bishop, 2017). Although the very existence of the MNS remains debated to this day, many authors have argued that empathic skill could be partly dependent on the activity of the MNS since recent evidence suggests that empathy processes are a associated to the MNS activity (Brown, Gonzalez-Liencres, Tas, \& Brune, 2016; Peled-Avron, Goldstein, Yellinek, Weissman-Fogel, \& Shamay-Tsoory, 2018; Woodruff, Martin, \& Bilyk, 2011). This functional association between MNS and empathy stems from previous studies showing that mirror neurons are similarly activated during the execution, observation and imagination of an action, which is in line with the notion that empathy is based on a mechanism of resonance between oneself and others (Hoenen, Lubke, \& Pause, 2015).

MNS activity is typically studied through the mu rhythm or sensorimotor rhythm. The mu rhythm is characterized by oscillations between $8-13 \mathrm{~Hz}$ for which maximal 
activity comes from the motor and sensorimotor cortices (Hobson and Bishop, 2017; Pineda, 2005). When a movement is initiated, observed or imagined, the mu rhythm desynchronizes, therefore causing a decrease of its spectral power observable on the EEG signal (Neuper, Wörtz, \& Pfurtscheller, 2006). A comparable pattern of mu suppression or desynchronization is observed between processing and expression of a given emotion, which supports the validity of EEG as an objective method to study mu suppression as a proxy of empathy (Hobson and Bishop, 2017). A greater mu rhythm suppression has been associated with a higher score on validated empathy questionnaires in young populations (Brown, et al., 2016; Peled-Avron, et al., 2018; Woodruff, et al., 2011). Moreover, the nature and valence of the emotional stimuli as well as participants sex seem to influence its modulation. A greater mu suppression is observed for facial stimuli compared to nonhuman stimuli (Moore, et al., 2012). A similar mu rhythm result pattern is observed for painful as opposed to neutral stimuli (Perry, Bentin, Bartal, Lamm, \& Decety, 2010). Females were also shown to exhibit significantly greater mu rhythm suppression during a pain empathy task. These findings support previous questionnaire-based evidence of the superiority of females in emotion decoding and empathic skills (Yang, Decety, Lee, Chen, \& Cheng, 2009). Importantly, these sex differences seem to be stable across the lifespan (Christov-Moore et al., 2014; O'Brien, Konrath, Gruhn, \& Hagen, 2013; Tracy and Giummarra, 2017).

Given the paucity of evidence supporting the association between empathy and human MNS function, the primary goal of this study is to characterize the EEG substrates of empathy by using an objective measure, namely the mu suppression, during the observation of emotional facial expressions (EFE). Little is known as to whether empathy processes tend to decline with normal healthy aging, and how this could correlate with the underlying neural substrates. Thus, our second goal is to characterize the effects of 
age on the neurophysiological response underlying empathy from an intergenerational perspective. More specifically, the present study will compare mu rhythm changes during observation of joyful, fearful and neutral EFEs in young adults (18-25 years) and seniors (55-75 years). These emotion-specific mu rhythm changes will be contrasted with a validated, self-reported empathy questionnaire. In light of age-related changes occurring at a cortical level combined with previous fMRI evidence of lower brain activation to emotional stimuli, it is expected that the aging group would exhibit a significantly reduced suppression of mu rhythm for emotional stimuli as opposed to neutral stimuli. Furthermore, knowing that females brain response to the observation of emotions experienced by others are significantly enhanced relative to that of males (Tracy and Giummarra, 2017), it is expected that females would show greater mu rhythm suppression across age groups. Finally, we expect to find an association between mu rhythm desynchronization and scores on the Quotient of Empathy scale.

\section{Methods}

\section{Participants}

A total of 67 participants were recruited and divided into two groups, one including young adults aged 18-25 and one consisting of aging adults aged 55-75. One young adult female and one senior male were excluded from further analyses as depression/anxiety scores on screening questionnaires exceeded established clinical thresholds $(\mathrm{BAI}=17$ et $\mathrm{BDI}=21$; (Beck, Steer, Ball, \& Ranieri, 1996)). The final sample consisted of 65 people, including 33 young adults (Mean age $=20.03, S D=1.47 ; 14$ females) and 32 seniors (Mean age $=$ $62.15, S D=4.35 ; 17$ females). All participants were right-handed and had normal or corrected vision. Table 1 presents demographic and clinical characteristics of the sample. Only age between groups was significantly different, $F(1,61)=2684,07, p<, 001$. Young 
adults were recruited from a database of undergraduate students interested in participating in studies conducted by various laboratories from the Cognition, Neurosciences, Affect et Comportements (COGNAC) research group at the Université du Québec à TroisRivières. Seniors were recruited through an advertisement on the Université du troisième age's website, a Université du Québec à Trois-Rivières initiative to facilitate access to university education for people aged 50 and over.

[Insert Table 1 around here]

Table 1. Between-group comparisons in demographic and clinical information $(N=65)$

\begin{tabular}{cccccc}
\hline & & Age & $\begin{array}{c}\text { Years of } \\
\text { scolarity }\end{array}$ & BDI-II & BAI \\
\hline \multirow{2}{*}{ Seniors } & Females $(n=17)$ & $61.69 \pm 3.77$ & $14.82 \pm 2.58$ & $3.24 \pm 2.54$ & $3.76 \pm 3.38$ \\
(55-75 y.o.) & Males $(n=15)$ & $62.67 \pm 5.01$ & $14.13 \pm 2.20$ & $3.00 \pm 3.44$ & $4.20 \pm 4.20$ \\
& Total $(n=32)$ & $62.15 \pm 4.35$ & $14.50 \pm 2.40$ & $3.12 \pm 2.95$ & $3.97 \pm 3.73$ \\
\hline \multirow{2}{*}{ Young adults } & Females $(n=14)$ & $20.01 \pm 1.22$ & $14.21 \pm 1.59$ & $4.79 \pm 2.69$ & $6.64 \pm 3.61$ \\
$(18-35$ y.o. $)$ & Males $(n=19)$ & $20.04 \pm 1.66$ & $13.74 \pm 1.66$ & $2.79 \pm 2.02$ & $3.84 \pm 3.32$ \\
& Total $(n=33)$ & $20.03 \pm 1.47$ & $13.94 \pm 1.62$ & $3.64 \pm 2.50$ & $5.03 \pm 3.67$ \\
\hline & GROUP $*$ SEX & 0.346 & 0.04 & 1.74 & 3.21 \\
& $F(1,61)=$ & $(p=.559)$ & $(p=.836)$ & $(p=.193)$ & $(p=.078)$ \\
& GROUP & $\mathbf{2 6 8 4 . 0 7}$ & 0.97 & 1.005 & 1.95 \\
& $F(1,61)=$ & $(p<.001)$ & $(p=.330)$ & $(p=.168)$ & $(p=.320)$ \\
& SEX & 0.39 & 1.30 & 2.79 & 1.72 \\
& $F(1,61)=$ & $(p=.535)$ & $(p=.259)$ & $(p=.195)$ & $(p=.100)$ \\
\hline
\end{tabular}

BDI-II = Beck Depression Inventory-II; BAI = Beck Anxiety Inventory;

Numbers are presented as Mean \pm SD

\section{General procedure}

Initial contact with each participant was made on the phone to go through their medical history and validate if they met the following eligibility criteria: no previous history of traumatic brain injury or sports-related concussion, no history of alcohol or substance abuse, no health problem requiring regular medication, no diagnosed psychiatric disorder or learning disability. A single 90-minute session was carried out to complete clinical questionnaires and administer the experimental task. A financial compensation of \$50CAD was given at the end of the experiment in exchange for their time and travel 
expenses. All participants gave written informed consent for the study, which was approved by the local Ethics Committee of the Université du Québec à Trois-Rivières.

\section{Materials}

\section{Clinical questionnaires}

Given that mood influences empathy (Li, Meng, Li, Yang, \& Yuan, 2017), participants completed validated anxiety and depression questionnaires. The Beck Depression Inventory (BDI-II; Beck, et al. (1996)) and Beck's Anxiety Inventory (BAI; Beck, Epstein, Brown, \& Steer (1988)) each contain 21 items used to measure symptom severity associated with clinical depression and clinical anxiety, respectively. Participants who reported moderate to severe symptoms of depression or anxiety were excluded.

\section{Empathy questionnaire}

The validated French version of the Quotient of Empathy (QE) scale was used as a selfreported measure of empathy (Baron-Cohen and Wheelwright (2004). This 60-item questionnaire contains 40 items directly assessing empathy, while the remaining 20 items are meant to distract the respondent from focusing on the empathic content of the tool. Responses are given on a four-point Likert scale, ranging from 1 (strongly disagree) to 4 (strongly agree). Scores vary between 0 and 80 , where a score inferior to 33 is considered as low empathy, a score between 33 and 52 is considered as moderate empathy and a score higher than 52 is considered as high empathy. The French validation has good psychometric qualities, both in terms of reliability $(r=0.97)$ and internal consistency (a = 0.92) (Lepage, Lortie, Taschereau-Dumouchel, \& Théoret, 2009). 
Empathy through an emotional facial expression task

The experimental procedure consisted of five blocks of 42 video clips. For each block, $14 \mathrm{EFE}$ of fear, $14 \mathrm{EFE}$ of joy and 14 neutral EFE were presented on a computer screen in random order. The presented stimuli were dynamic and colourful faces, expressed by seven actors and seven actresses, from a standardized bank of emotional facial expressions (Simon, Craig, Gosselin, Belin, \& Rainville, 2008). Figure 1 represents an example of an actor presenting all three types of EFE. Each trial started by a 500-ms videoclip of an EFE changing from a neutral to an emotional expression and was followed by an interval of $1500 \mathrm{~ms}$ during which no stimulus was presented. A central fixation cross was then presented on the screen for a random duration (between $1000 \mathrm{~ms}$ and $2000 \mathrm{~ms}$ ) and was used to indicate the occurrence of a new trial. Participants were asked to try to experience the emotion expressed on the screen during the $1500 \mathrm{~ms}$ following the 500-ms EFE videoclip. They also had to maintain a neutral facial expression during the presentation of the different stimuli so that the task only elicits brain activity inherent to the observation of emotional facial expressions. Each participant sat on a straight back chair at $70 \mathrm{~cm}$ from the computer monitor in a dimly lit testing room. Participants were asked to keep their eyes open and avoid moving or contracting their body during the entire session.

[Insert Figure 1 around here]

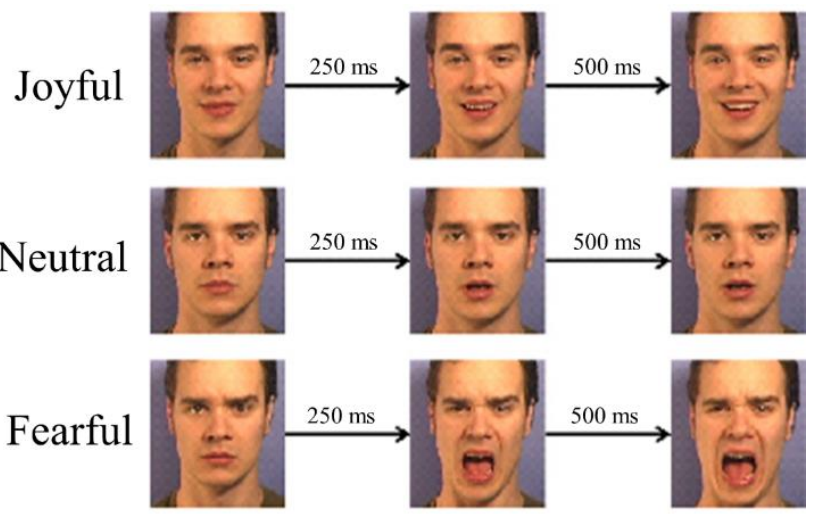

Figure 1. Typical examples of an actor doing all three types of emotional facial expressions lasting $500 \mathrm{~ms}$. 


\section{Data acquisition and analysis}

\section{EEG recordings}

Brain activity was recorded from 64 electrodes placed on a cap covering the participant's scalp according to the International System 10-20 and referenced to the vertex. Two electrodes placed on left and right mastoids replaced the TP9 and TP10 electrode sites. All electrodes were referenced to the left mastoid and data were re-referenced off-line to the algebraic average of the mastoid electrodes (Luck, 2014). Four additional electrodes were placed around the eyes, two on the temporal tip (HEOG) and two on the infra/supraorbital eye contour (VEOG) to control for eye movement artefacts. The impedance was kept under $10 \mathrm{k} \Omega$ throughout the experimental task. EEG recording was continuous and digitized at a sampling rate of $512 \mathrm{~Hz}$ with low/high-pass filters set at 100 and $0.01 \mathrm{~Hz}$, respectively.

\section{Data processing}

EEG data was analyzed using Brain Vision Analyzer 2.0. For each experimental condition, the interpretation of the electrophysiological response inherent to EFE perception focused on mu rhythm modulation generated by the stimuli. More specifically, this modulation was recorded and analyzed from $\mathrm{C} 5, \mathrm{C} 3, \mathrm{C} 1, \mathrm{CZ}, \mathrm{C} 2, \mathrm{C} 4$ and $\mathrm{C} 6$ electrodes, which correspond to the principal motor activity sites where maximal MNS activity is recorded from (Hobson and Bishop, 2017; Muthukumaraswamy, Johnson, \& McNair, 2004). Individual averages for each of the electrodes of interest were made and averaged to evaluate all event-related disturbances according to the experimental condition. All analyses were performed on EEG recorded within -1000 ms to $2000 \mathrm{~ms}$ from stimulus onset. In addition, Fast-Fourier Transform spectral analyses were performed to extract mu rhythm modulation across each of the three types of emotional 
facial expression in a time window ranging from 500-1500 ms relative to stimulus onset. The selected time window is based on previous validation work by Moore, et al. (2012) that showed maximal mu rhythm modulation starting $500 \mathrm{~ms}$ after stimulus onset with the observation of happy and disgusted faces. Finally, trials contaminated with eye blinks $(\mathrm{VEOG}>100 \mu \mathrm{V})$, horizontal eye movements $(\mathrm{HEOG}>35 \mu \mathrm{V})$ and/or artefacts $(>80 \mu \mathrm{V})$ were identified and excluded using an established independent component analysis procedure (Jung et al., 2000). To this end, three participants, a young female, a young male and a senior female were excluded from further analyses, bringing the total sample to 63 participants due to an excessive trial rejection rate caused by repeated eye blinks and movements.

\section{Statistical analyses}

Between-groups differences in the electrophysiological response across emotional facial expression types were analyzed according to a mixed ( 2 X 2 X 3) ANOVA, with Group and sex as between-subjects factors and EFE valence (joyful, fearful, neutral) as the within-subject factor. Correlations were computed between the QE score, the electrophysiological response presumably related to the empathic experience. The degrees of freedom were corrected with the Greenhouse-Geisser method when the sphericity of Mauchly was not respected. Two-tailed $p$ values less than .05 were considered statistically significant.

\section{Results}

\section{Descriptive data}

Table 2 shows descriptive statistics of averaged mu rhythm suppression from pooled electrodes during the 500-1500 ms time window post-stimulus onset and the self-reported score on the QE scale. 
[Insert Table 2 around here]

Table 2. Descriptive statistics of mu rhythm during the 500-1500 ms post-stimulus and QE scores

\begin{tabular}{cccccccccc}
\hline & \multicolumn{3}{c}{ Seniors } & \multicolumn{3}{c}{ Young adults } & \multicolumn{3}{c}{ Total } \\
\cline { 2 - 10 } & $\begin{array}{c}\text { Females } \\
(n=16)\end{array}$ & $\begin{array}{c}\text { Males } \\
(n=15)\end{array}$ & $\begin{array}{c}\text { Total } \\
(n=31)\end{array}$ & $\begin{array}{c}\text { Females } \\
(n=13)\end{array}$ & $\begin{array}{c}\text { Males } \\
(n=19)\end{array}$ & $\begin{array}{c}\text { Total } \\
(n=32)\end{array}$ & $\begin{array}{c}\text { Females } \\
(n=29)\end{array}$ & $\begin{array}{c}\text { Males } \\
(n=34)\end{array}$ & $\begin{array}{c}\text { Total } \\
(n=63)\end{array}$ \\
\hline \multirow{2}{*}{ Joyful EFE } & 5.51 & 6.24 & 5.86 & 5.14 & 6.89 & 6.18 & 5.34 & 6.60 & 6.02 \\
& \pm 1.94 & \pm 1.65 & \pm 1.82 & \pm 1.59 & \pm 2.08 & \pm 2.06 & \pm 1.77 & \pm 1.90 & \pm 1.93 \\
Fearful EFE & 5.52 & 6.33 & 5.91 & 5.37 & 7.04 & 6.36 & 5.45 & 6.73 & 6.14 \\
& \pm 1.91 & \pm 1.83 & \pm 1.88 & \pm 1.40 & \pm 2.11 & \pm 2.01 & \pm 1.68 & \pm 2.00 & \pm 1.95 \\
Neutral EFE & 5.12 & 6.50 & 5.79 & 5.87 & 7.24 & 6.69 & 5.46 & 6.92 & 6.24 \\
& \pm 1.71 & \pm 1.79 & \pm 1.86 & \pm 1.97 & \pm 1.93 & \pm 2.03 & \pm 1.83 & \pm 1.88 & \pm 1.98 \\
QE & 40.52 & 34.73 & 37.81 & 42.79 & 42.16 & 42.42 & 41.55 & 38.88 & 40.15 \\
& \pm 9.73 & \pm 8.54 & \pm 9.51 & \pm 8.17 & \pm 9.25 & \pm 8.67 & \pm 8.17 & \pm 9.57 & \pm 9.32 \\
\hline
\end{tabular}

$\mathrm{EFE}$ = emotional facial expression; QE = Quotient of Empathy;

Numbers are presented as Mean \pm SD

\section{Neurophysiological data}

First, we performed a mixed factorial ANOVA on the mu rhythm with Group (young or senior) and Sex (male or female) as between-subjects factors and the EFE Valence (3 levels: neutral, joy, fear) as the within-subject factor. The Group*Sex*Valence interaction revealed to be statistically significant $F(1.74,102.80)=4.04 ; p=.025 ; \eta p 2=$ .064). The latter analysis also revealed statistically significant Group*Valence interaction $(F(1.74,102.80)=4.66 ; p=.015 ; \eta p 2=.073)$ and a main effect of $\operatorname{Sex}((F(1,59)=7.86 ;$ $p=.007 ; \eta \mathrm{p} 2=.118)$. No other statistical significant effect was found [Main effect of Group $(F(1,59)=0.81 ; p=.372 ; \eta p 2=.014)$, Valence*Sex interaction effect $(F(1.74$ $102.80)=1.74 ; p=.690 ; \eta p 2=.006)$ and Group $* \operatorname{Sex}(F(1,59)=0.45 ; p=.503 ; \eta p 2=$ .008]. To further investigate the Group*Valence interaction (depicted in Figure 2), two within-subjects ANOVAs were performed according to age groups, regardless of sex. The electrophysiological response of young adults differed significantly according to the type of $\operatorname{EFE}(F(1.57,48.50)=5.12 ; p=.015 ; \eta p 2=.142)$. Contrast analyses showed that the mu rhythm suppression to neutral EFE was significantly smaller than that elicited by joyful $\operatorname{EFE}(F(1,31)=6.55 ; p=.016 ; \eta p 2=.174)$ and fearful $\operatorname{EFE}(F(1,31)=5.36 ; p=$ 
$.027 ; \eta p 2=.147)$. However, among the senior group, mu rhythm evoked by the presentation of EFE was not significantly different according to the valence of EFEs $(F(2$, $60)=0.63 ; p=.537 ; \eta p 2=.020)$. Descriptive data indicate that the young adults reacted significantly more to active EFE relative to neutral EFE.

[Insert Figure 2 around here]

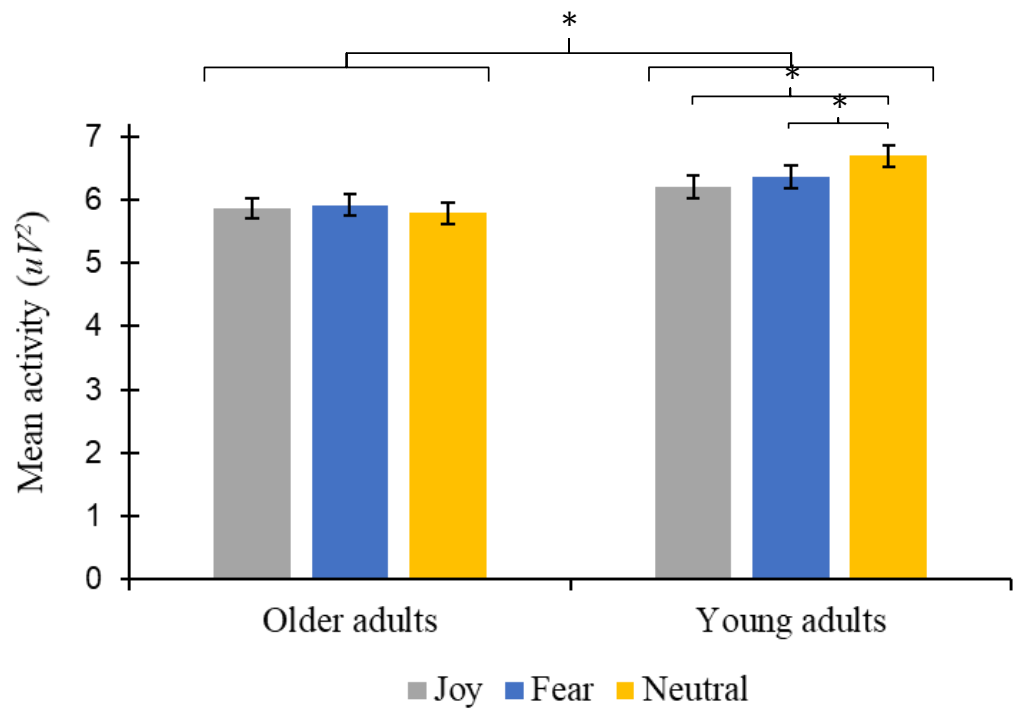

Figure 2. Baseline-corrected mu rhythm activity (8-13 Hz) between 500 and $1000 \mathrm{~ms}$ post-stimulus presentation in older and younger adults.

$*=p<0.05$. Error bars represent standard error of the mean.

In light of the main effect of sex, we performed 2 X 3 ANOVAs separately in male and female participants with Group (young or senior) as the between-subjects factor and EFE Valence (3 levels: neutral, joy, fear) as the within-subject factor. As shown in Figure 3 , a statistically significant main effect of Valence $(F(2,64)=4.52 ; p=.015 ; \eta p 2=$ .124) was found in males. Contrast analyses showed a statistically significant difference between joyful and neutral $\operatorname{EFE}(F(1,32)=8.68 p=.006 ; \eta p 2=.213)$, but not between fearful and neutral EFE $(F(1,32)=2.93 ; p=.096 ; \eta p 2=.084)$. Other statistical tests extracted from the latter mixed ANOVA conducted in males did not reveal to be significant [Group*Valence interaction, $(F(2,64)=0.11 ; p=.896 ; \eta p 2=.003$; main effect of Group $(F(1,32)=1.14 ; p=.294 ; \eta p 2=.034]$. In females, the 2 X 3 ANOVA revealed a statistically significant Group*Valence interaction $(F(1.53,41.30)=5.99 ; p=.009$; 
$\eta p 2=.182)$, while the main effects of Group $(F(1,27)=0.015 ; p=.902 ; \eta p 2=.001)$ or Valence $(F(1.53,41.30)=0.30 ; p=.684 ; \eta p 2=.011)$ were not significant. This result indicates changes in mu rhythm response as a function of age specific to females, but not in males.

[Insert Figure 3 around here]

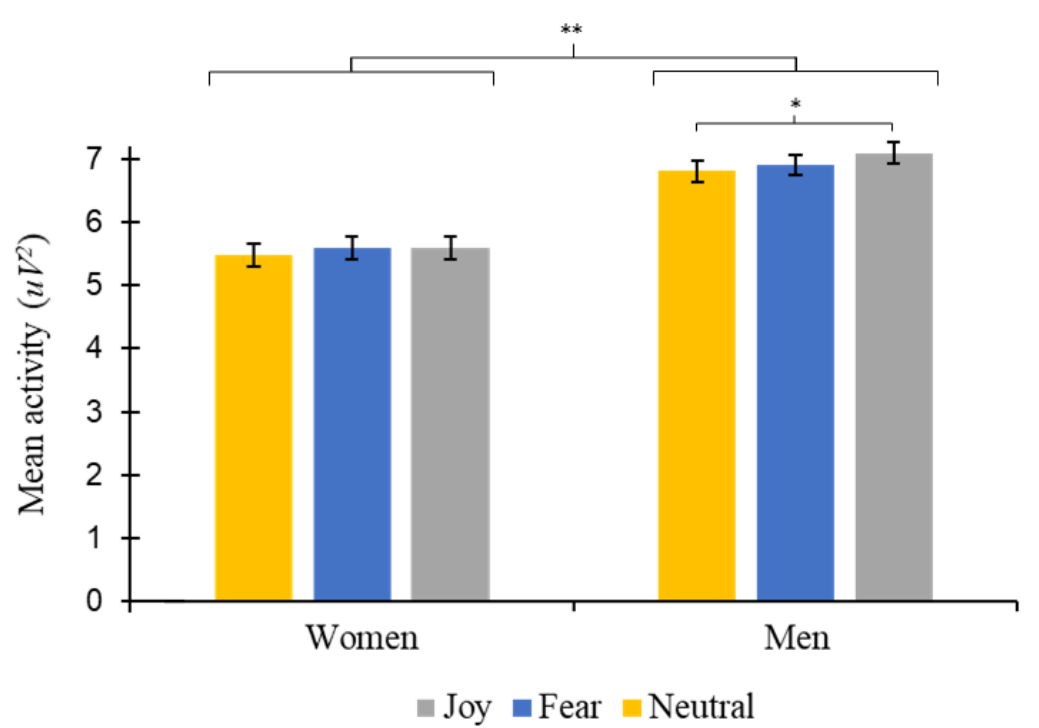

Figure 3. Baseline-corrected mu rhythm activity $(8-13 \mathrm{~Hz})$ between 500 and $1000 \mathrm{~ms}$ post-stimulus presentation in women and men.

$*=p<0.05 . * *=p<.01$. Error bars represent standard error of the mean.

Additional within-subjects ANOVAs for each age group in females were performed. In aging females, the modulation of mu rhythm was significantly different across EFE $(F(2,30)=4.19 ; p=.025 ; \eta p 2=.218)$. Contrast analyses showed that the response to neutral $\mathrm{EFE}$ was greater than to joy $\operatorname{EFE}(F(1,15)=5.72 ; p=.03 ; \eta p 2=.276)$ and fear $\operatorname{EFE}(F(1,15)=5.08 ; p=.04 ; \eta p 2=.253)$. However, in the young females group, mu rhythm elicited by the presentation of the EFE was not significantly different according to the different EFE presented $(F(1.31,15.67)=2.60 ; p=.121 ; \eta p 2=.178)$. Descriptive data indicate that contrary to expectations, the mu rhythm of aging females evoked by neutral EFE was more suppressed than for joyful or fearful stimuli. 


\section{Self-reported questionnaire on Empathy}

Finally, we performed a 2 X 2 ANOVA with Group (young or senior) and sex (male or female) as between-subjects factors on the QE score. The Group*Sex interaction did not reach statistical significance $(F(1,61)=1.32 ; p=.255 ; \eta p 2=.021)$, neither did the main effect of $\operatorname{sex}(F(1,61)=2.04 ; p=.158 ; \eta p 2=.032)$. In contrast, the main effect of Group $(F(1,61)=4.64 ; p=.035 ; \eta p 2=.071)$ was found to be statistically significant, indicating a lower score on the empathy questionnaire in aging subjects.

\section{Correlational analyses}

We performed a series of Pearson correlational analyses involving QE score and the amplitude of the mu rhythm evoked by EFE stimuli. Analyses including all participants could not find any association between QE score and emotional facial expression conditions $($ Joy: $r(61)=-0.004, p=.978 ;$ Fear $: r(61)=-0.005, p=.978$; Neutral $: r(61)$ $=-0.047, p=.978)$. Given the statistically significant main effect of sex on mu rhythm suppression, we carried out a series of Pearson correlations after having stratified according to sex. These correlations revealed statistically significant correlations between QE score and mu rhythm evoked by EFE in females [Joyful: $r(28)=-0.39 p=.039$; Fearful: $r(28)=-0.43, p=.023$; Neutral: $r(28)=-0.465, p=.013]$, but not in males [Joyful: $r(33)=0.25 p=.16$; Fearful: $r(33)=0.24, p=.188$; Neutral: $r(33)=0.25, p=$ $.0157]$.

\section{Discussion}

The current study investigated the effects of age and sex on MNS activity through mu rhythm modulation elicited during the observation of emotional facial expression stimuli. We also sought to investigate potential relationships with empathy, a higher-level determinant of social adaptation that is thought to be a function of the human MNS. 
Firstly, our results show age-related differences in EFE processing, where young adults exhibited the expected increased responsiveness to emotional stimuli relative to neutral stimuli (Perry, Troje, \& Bentin, 2010) as opposed to aging individuals whose mu rhythm response did not discriminate between neutral and emotional stimuli. Given that decoding and processing of emotional stimuli through mu rhythm have been linked to empathic skill (Moore, et al., 2012; Perry, Bentin, et al., 2010; Yang, et al., 2009), it would stand to reason that the suppressed mu rhythm response found in aging adults could at least partly underlie age-related changes in empathy (Isaacowitz and Stanley, 2011; Ruffman, Henry, Livingstone, \& Phillips, 2008; Sullivan, Campbell, Hutton, \& Ruffman, 2017).

As expected, we also found that females exhibited greater mu rhythm desynchronization (i.e.; greater mu rhythm response) relative to males during the observation of emotional stimuli, independently of their age (Cheng et al., 2008; Cheng, Yang, Lin, Lee, \& Decety, 2008). This sex difference is in keeping with mu rhythm data obtained in a pain observation paradigm (Yang, et al., 2009). Moreover, the greater mu rhythm response to emotional stimuli in females found herein is also in line with previous demonstrations that cortical regions involved in MNS activity and empathy processes were more activated in young females than in young males (Ruigrok et al., 2014; SchulteRuther, Markowitsch, Shah, Fink, \& Piefke, 2008).

Results in young adults from the current study revealing differences according to the emotional valence also support the notion that mu suppression is a valid and objective proxy to study empathy (Moore, et al., 2012; Perry, Bentin, et al., 2010). Indeed, a greater mu suppression pattern was observed after joyful and fearful EFE relative to neutral EFE. Given that happiness and fear are two of the most easily recognizable emotions, it is not surprising that similar mu suppression patterns were found between joyful and fearful facial expressions (Rodger, Vizioli, Ouyang, \& Caldara, 2015). 
As for the subjective QE-related outcomes, current study findings show a significant main effect of group, where the older participants scored lower on the standardized Quotient of Empathy scale compared to young adults. This result pattern is also consistent with previous findings suggesting a decrease in empathy during aging (Gruhn, Rebucal, Diehl, Lumley, \& Labouvie-Vief, 2008; O'Brien, et al., 2013). Interestingly, mu rhythm modulation to emotional EFE was found to significantly correlate with scores on the standardized Quotient of Empathy scale, further supporting the validity of mu rhythm modulation as an objective electrophysiological marker of empathy. More specifically, our results indicate that an increased mu suppression to emotional EFE is associated with superior self-reported empathic capacities. This study finding is in keeping with previous studies showing an association between mu rhythm modulation and self-reported empathy (Brown, et al., 2016; Cheng, Yang, et al., 2008; Woodruff, et al., 2011). It is important to note, however, that this association was only found in females.

Surprisingly, stratifications according to sex and age groups revealed an unexpected result pattern in that older females exhibited a significantly greater mu suppression following the observation of neutral EFE as opposed to joyful or fearful EFE. In keeping with previous cross-sectional fMRI studies suggesting age-related efficiency loss in emotional processing (Chen, et al., 2014; Riva, et al., 2018), the latter finding suggests that mu rhythm of females elicited by emotional EFE are more subjected to age-related effects. In a recent study conducted by Riva, et al. (2018) in teens, young and older females, data derived from fMRI were found to be more sensitive to detect the early signs of empathy reduction than self-reported measures, especially in older women.

\section{Limitations}


One limitation of this study concerns the difficulty to dissociate mu rhythm recorded over the primary motor cortex from posterior alpha activity as they both share the same spectral band but testify to different phenomena (Perry, Troje, et al., 2010). More specifically, mu rhythm appears to peak around central cortical areas and becomes desynchronized following the execution or observation of a biological movement, whereas posterior alpha rhythm is minimally affected by these actions and seems to preferentially respond to the opening and closing of eyes (Pineda, 2005). Since our data was collected from central electrodes and that all participants received the same instructions, namely to keep eyes open and try to experience the presented emotion, we assume, as per several other emotion and mu rhythm studies, that recorded activity from central electrodes reflected mu rhythm activation (Peled-Avron, et al., 2018; Woodruff, et al., 2011). Secondly, it would also appear possible that the degree of familiarity of the presented stimuli may have influenced the emotional experience of the aging group. Indeed, as emotional facial expressions were expressed exclusively by young actors, aging participants may have connected less with the observed stimuli, which may have hindered their empathic experience. Accordingly, it has been shown that age-related empathy reductions in seniors when performing an empathy task tended to disappear when the latter were presented emotional stimuli adjusted to their age group (Kunzmann and Isaacowitz, 2017; Wieck and Kunzmann, 2015). Finally, this cross-sectional study design cannot exclude the well-documented cohort or intergenerational bias (Heo et al., 2017; Keyes, Utz, Robinson, \& Li, 2010).

\section{Conclusion}

In sum, our results suggest a significant attenuation of the mu rhythm to emotional stimuli specific to the aging cohort. Aging females, in particular, experience the most important changes in mu rhythm modulation. However, the present study replicated previous 
findings of a greater neurophysiological response to EFE in females, a finding that significantly correlated with the questionnaire-based measure of empathy. Finally, the present study further supports the pertinence of mu rhythm recordings during the observation of emotional facial expression stimuli as an objective proxy to study social cognition processes.

\section{Acknowledgements}

We would like to thank the participants who took their time to complete the task. 
References:

Bailey, P. E., \& Henry, J. D. (2009). Subconscious facial expression mimicry is preserved in older adulthood. Psychology and Aging, 24(4), pp. 995-1000. doi:10.1037/a0015789 Retrieved from https://www.ncbi.nlm.nih.gov/pubmed/20025413

Bailey, P. E., Henry, J. D., \& Von Hippel, W. (2008). Empathy and social functioning in late adulthood. Aging \& Mental Health, 12(4), pp. 499-503. doi:10.1080/13607860802224243 Retrieved from https://www.ncbi.nlm.nih.gov/pubmed/18791898

Baron-Cohen, S., \& Wheelwright, S. (2004). The empathy quotient: an investigation of adults with Asperger syndrome or high functioning autism, and normal sex differences. Journal of Autism and Developmental Disorders, 34(2), pp. 163175. Retrieved from https://www.ncbi.nlm.nih.gov/pubmed/15162935

Beck, A. T., Epstein, N., Brown, G., \& Steer, R. A. (1988). An inventory for measuring clinical anxiety: psychometric properties. Journal of Consulting and Clinical Psychology, 56(6), pp. 893-897. Retrieved from https://www.ncbi.nlm.nih.gov/pubmed/3204199

Beck, A. T., Steer, R. A., Ball, R., \& Ranieri, W. (1996). Comparison of Beck Depression Inventories -IA and -II in psychiatric outpatients. Journal of Personality Assessment, 67(3), pp. 588-597. doi:10.1207/s15327752jpa6703_13 Retrieved from https://www.ncbi.nlm.nih.gov/pubmed/8991972

Brown, E. C., Gonzalez-Liencres, C., Tas, C., \& Brune, M. (2016). Reward modulates the mirror neuron system in schizophrenia: A study into the mu rhythm suppression, empathy, and mental state attribution. Social Neuroscience, 11(2), pp. 175-186. doi:10.1080/17470919.2015.1053982 Retrieved from https://www.ncbi.nlm.nih.gov/pubmed/26073271

Chen, Y. C., Chen, C. C., Decety, J., \& Cheng, Y. (2014). Aging is associated with changes in the neural circuits underlying empathy. Neurobiology of Aging, 35(4), pp. 827-836. doi:10.1016/j.neurobiolaging.2013.10.080 Retrieved from https://www.ncbi.nlm.nih.gov/pubmed/24211010

Cheng, Y., Lee, P. L., Yang, C. Y., Lin, C. P., Hung, D., \& Decety, J. (2008). Gender differences in the mu rhythm of the human mirror-neuron system. PloS One, 3(5), p e2113. doi:10.1371/journal.pone.0002113 Retrieved from https://www.ncbi.nlm.nih.gov/pubmed/18461176

https://www.ncbi.nlm.nih.gov/pmc/articles/PMC2361218/pdf/pone.0002113.pdf

Cheng, Y., Yang, C. Y., Lin, C. P., Lee, P. L., \& Decety, J. (2008). The perception of pain in others suppresses somatosensory oscillations: a magnetoencephalography study. Neuroimage, 40(4), pp. 1833-1840. 
doi:10.1016/j.neuroimage.2008.01.064 Retrieved from https://www.ncbi.nlm.nih.gov/pubmed/18353686

Christov-Moore, L., Simpson, E. A., Coude, G., Grigaityte, K., Iacoboni, M., \& Ferrari, P. F. (2014). Empathy: gender effects in brain and behavior. Neuroscience and Biobehavioral Reviews, 46 Pt 4, pp. 604-627.

doi:10.1016/j.neubiorev.2014.09.001 Retrieved from https://www.ncbi.nlm.nih.gov/pubmed/25236781

Decety, J., \& Jackson, P. L. (2004). The functional architecture of human empathy. Behavioral and Cognitive Neuroscience Reviews, 3(2), pp. 71-100. doi:10.1177/1534582304267187 Retrieved from https://www.ncbi.nlm.nih.gov/pubmed/15537986

Decety, J., \& Svetlova, M. (2012). Putting together phylogenetic and ontogenetic perspectives on empathy. Developmental Cognitive Neuroscience, 2(1), pp. 124. doi:10.1016/j.den.2011.05.003 Retrieved from https://www.ncbi.nlm.nih.gov/pubmed/22682726

Gruhn, D., Rebucal, K., Diehl, M., Lumley, M., \& Labouvie-Vief, G. (2008). Empathy across the adult lifespan: Longitudinal and experience-sampling findings. Emotion, 8(6), pp. 753-765. doi:10.1037/a0014123 Retrieved from https://www.ncbi.nlm.nih.gov/pubmed/19102586

Henry, J. D., Phillips, L. H., Ruffman, T., \& Bailey, P. E. (2013). A meta-analytic review of age differences in theory of mind. Psychology and Aging, 28(3), pp. 826-839. doi:10.1037/a0030677 Retrieved from https://www.ncbi.nlm.nih.gov/pubmed/23276217

Heo, J., Jeon, S. Y., Oh, C. M., Hwang, J., Oh, J., \& Cho, Y. (2017). The unrealized potential: cohort effects and age-period-cohort analysis. Epidemiol Health, 39, p e2017056. doi:10.4178/epih.e2017056 Retrieved from https://www.ncbi.nlm.nih.gov/pubmed/29309721

Hobson, H. M., \& Bishop, D. V. (2017). The interpretation of mu suppression as an index of mirror neuron activity: past, present and future. $R$ Soc Open Sci, 4(3), p 160662. doi:10.1098/rsos.160662 Retrieved from https://www.ncbi.nlm.nih.gov/pubmed/28405354

Hoenen, M., Lubke, K. T., \& Pause, B. M. (2015). Somatosensory mu activity reflects imagined pain intensity of others. Psychophysiology, 52(12), pp. 1551-1558. doi:10.1111/psyp.12522 Retrieved from https://www.ncbi.nlm.nih.gov/pubmed/26379210

Hühnel, I., Fölster, M., Werheid, K., \& Hess, U. (2014). Empathic reactions of younger and older adults: No age related decline in affective responding. Journal of Experimental Social Psychology, 50, pp. 136-143. doi:10.1016/j.jesp.2013.09.011

Isaacowitz, D. M., \& Stanley, J. T. (2011). Bringing an Ecological Perspective to the Study of Aging and Recognition of Emotional Facial Expressions: Past, Current, and Future Methods. J Nonverbal Behav, 35(4), pp. 261-278. 
doi:10.1007/s10919-011-0113-6 Retrieved from https://www.ncbi.nlm.nih.gov/pubmed/22125354

Jung, T. P., Makeig, S., Humphries, C., Lee, T. W., McKeown, M. J., Iragui, V., \& Sejnowski, T. J. (2000). Removing electroencephalographic artifacts by blind source separation. Psychophysiology, 37(2), pp. 163-178. Retrieved from https://www.ncbi.nlm.nih.gov/pubmed/10731767

Keyes, K. M., Utz, R. L., Robinson, W., \& Li, G. (2010). What is a cohort effect? Comparison of three statistical methods for modeling cohort effects in obesity prevalence in the United States, 1971-2006. Social Science and Medicine, 70(7), pp. 1100-1108. doi:10.1016/j.socscimed.2009.12.018 Retrieved from https://www.ncbi.nlm.nih.gov/pubmed/20122771

Kunzmann, U., \& Isaacowitz, D. (2017). Emotional Aging: Taking the Immediate Context Seriously. Research in Human Development, 14(3), pp. 182-199. doi:10.1080/15427609.2017.1340048

Lepage, J.-F., Lortie, M., Taschereau-Dumouchel, V., \& Théoret, H. (2009). Validation of French-Canadian versions of the Empathy Quotient and Autism Spectrum Quotient. Canadian Journal of Behavioural Science / Revue canadienne des sciences du comportement, 41(4), pp. 272-276. doi:10.1037/a0016248

Li, X., Meng, X., Li, H., Yang, J., \& Yuan, J. (2017). The impact of mood on empathy for pain: Evidence from an EEG study. Psychophysiology, 54(9), pp. 1311-1322. doi:10.1111/psyp.12882 Retrieved from https://www.ncbi.nlm.nih.gov/pubmed/28449372

Luck, S. J. (2014). An introduction to the Event-Related Potential Technique (2 ed.) Cambridge, MA: The MIT Press.

Moore, A., Gorodnitsky, I., \& Pineda, J. (2012). EEG mu component responses to viewing emotional faces. Behavioural Brain Research, 226(1), pp. 309-316. doi:10.1016/j.bbr.2011.07.048 Retrieved from https://www.ncbi.nlm.nih.gov/pubmed/21835208

Moran, J. M. (2013). Lifespan development: the effects of typical aging on theory of mind. Behavioural Brain Research, 237, pp. 32-40.

doi:10.1016/j.bbr.2012.09.020 Retrieved from https://www.ncbi.nlm.nih.gov/pubmed/23000532

Muthukumaraswamy, S. D., Johnson, B. W., \& McNair, N. A. (2004). Mu rhythm modulation during observation of an object-directed grasp. Brain Research: Cognitive Brain Research, 19(2), pp. 195-201. doi:10.1016/j.cogbrainres.2003.12.001 Retrieved from https://www.ncbi.nlm.nih.gov/pubmed/15019715

Narme, P., Mouras, H., Loas, G., Krystkowiak, P., Roussel, M., Boucart, M., \& Godefroy, O. (2010). Vers une approche neuropsychologique de l'empathie. Revue de neuropsychologie, 2010/4(2), pp. 292-298. doi:10.1684/nrp.2010.0098 
Neumann, D., \& Westbury, H. R. (2011). The psychophysiological measurement of empathy. In D. J. Scapaletti (Ed.), Psychology of Empathy. New York: Nova Science Publishers, Inc.

Neuper, C., Wörtz, M., \& Pfurtscheller, G. (2006). ERD/ERS patterns reflecting sensorimotor activation and deactivation Event-Related Dynamics of Brain Oscillations (pp. 211-222).

O'Brien, E., Konrath, S. H., Gruhn, D., \& Hagen, A. L. (2013). Empathic concern and perspective taking: linear and quadratic effects of age across the adult life span. Journals of Gerontology. Series B: Psychological Sciences and Social Sciences, 68(2), pp. 168-175. doi:10.1093/geronb/gbs055 Retrieved from https://www.ncbi.nlm.nih.gov/pubmed/22865821

Peled-Avron, L., Goldstein, P., Yellinek, S., Weissman-Fogel, I., \& Shamay-Tsoory, S. G. (2018). Empathy during consoling touch is modulated by mu-rhythm: An EEG study. Neuropsychologia, 116(Pt A), pp. 68-74. doi:10.1016/j.neuropsychologia.2017.04.026 Retrieved from https://www.ncbi.nlm.nih.gov/pubmed/28442340

Pernigo, S., Gambina, G., Valbusa, V., Condoleo, M. T., Broggio, E., Beltramello, A., . . Moro, V. (2015). Behavioral and neural correlates of visual emotion discrimination and empathy in mild cognitive impairment. Behavioural Brain Research, 294, pp. 111-122. doi:10.1016/j.bbr.2015.07.047 Retrieved from https://www.ncbi.nlm.nih.gov/pubmed/26222787

Perry, A., Bentin, S., Bartal, I. B., Lamm, C., \& Decety, J. (2010). "Feeling" the pain of those who are different from us: Modulation of EEG in the mu/alpha range. Cognitive, Affective \& Behavioral Neuroscience, 10(4), pp. 493-504. doi:10.3758/CABN.10.4.493 Retrieved from https://www.ncbi.nlm.nih.gov/pubmed/21098810

Perry, A., Troje, N. F., \& Bentin, S. (2010). Exploring motor system contributions to the perception of social information: Evidence from EEG activity in the mu/alpha frequency range. Social Neuroscience, 5(3), pp. 272-284. doi:10.1080/17470910903395767 Retrieved from https://www.ncbi.nlm.nih.gov/pubmed/20169504

Pineda, J. A. (2005). The functional significance of mu rhythms: translating "seeing" and "hearing" into "doing". Brain Research: Brain Research Reviews, 50(1), pp. 57-68. doi:10.1016/j.brainresrev.2005.04.005 Retrieved from https://www.ncbi.nlm.nih.gov/pubmed/15925412

Preston, S. D., \& de Waal, F. B. M. (2002). Empathy: Its ultimate and proximate bases. Behavioral and Brain Sciences, 25(1), pp. 1-72.

Rayson, H., Bonaiuto, J. J., Ferrari, P. F., \& Murray, L. (2016). Mu desynchronization during observation and execution of facial expressions in 30-month-old children. Developmental Cognitive Neuroscience, 19, pp. 279-287.

doi:10.1016/j.dcn.2016.05.003 Retrieved from https://www.ncbi.nlm.nih.gov/pubmed/27261926 
Riva, F., Tschernegg, M., Chiesa, P. A., Wagner, I. C., Kronbichler, M., Lamm, C., \& Silani, G. (2018). Age-related differences in the neural correlates of empathy for pleasant and unpleasant touch in a female sample. Neurobiology of Aging, 65, pp. 7-17. doi:10.1016/j.neurobiolaging.2017.12.028 Retrieved from https://www.ncbi.nlm.nih.gov/pubmed/29407469

Rodger, H., Vizioli, L., Ouyang, X., \& Caldara, R. (2015). Mapping the development of facial expression recognition. Dev Sci, 18(6), pp. 926-939. doi:10.1111/desc.12281 Retrieved from https://www.ncbi.nlm.nih.gov/pubmed/25704672

Ruffman, T., Henry, J. D., Livingstone, V., \& Phillips, L. H. (2008). A meta-analytic review of emotion recognition and aging: implications for neuropsychological models of aging. Neuroscience and Biobehavioral Reviews, 32(4), pp. 863-881. doi:10.1016/j.neubiorev.2008.01.001 Retrieved from https://www.ncbi.nlm.nih.gov/pubmed/18276008

Ruigrok, A. N., Salimi-Khorshidi, G., Lai, M. C., Baron-Cohen, S., Lombardo, M. V., Tait, R. J., \& Suckling, J. (2014). A meta-analysis of sex differences in human brain structure. Neuroscience and Biobehavioral Reviews, 39, pp. 34-50. doi:10.1016/j.neubiorev.2013.12.004 Retrieved from https://www.ncbi.nlm.nih.gov/pubmed/24374381

Schulte-Ruther, M., Markowitsch, H. J., Shah, N. J., Fink, G. R., \& Piefke, M. (2008). Gender differences in brain networks supporting empathy. Neuroimage, 42(1), pp. 393-403. doi:10.1016/j.neuroimage.2008.04.180 Retrieved from https://www.ncbi.nlm.nih.gov/pubmed/18514546

Simon, D., Craig, K. D., Gosselin, F., Belin, P., \& Rainville, P. (2008). Recognition and discrimination of prototypical dynamic expressions of pain and emotions. Pain, 135(1-2), pp. 55-64. doi:10.1016/j.pain.2007.05.008 Retrieved from https://www.ncbi.nlm.nih.gov/pubmed/17583430

Sullivan, S., Campbell, A., Hutton, S. B., \& Ruffman, T. (2017). What's good for the goose is not good for the gander: Age and gender differences in scanning emotion faces. Journals of Gerontology. Series B: Psychological Sciences and Social Sciences, 72(3), pp. 441-447. doi:10.1093/geronb/gbv033 Retrieved from https://www.ncbi.nlm.nih.gov/pubmed/25969472

Sun, B., Luo, Z., Zhang, W., Li, W., \& Li, X. (2018). Age-related differences in affective and cognitive empathy: self-report and performance-based evidence. Neuropsychology, Development, and Cognition. Section B: Aging, Neuropsychology and Cognition, 25(5), pp. 655-672. doi:10.1080/13825585.2017.1360835 Retrieved from https://www.ncbi.nlm.nih.gov/pubmed/28774223

Sze, J. A., Gyurak, A., Goodkind, M. S., \& Levenson, R. W. (2012). Greater emotional empathy and prosocial behavior in late life. Emotion, 12(5), pp. 1129-1140. doi:10.1037/a0025011 Retrieved from https://www.ncbi.nlm.nih.gov/pubmed/21859198 
Tousignant, B., Eugene, F., \& Jackson, P. L. (2017). A developmental perspective on the neural bases of human empathy. Infant Behavior \& Development, 48(Pt A), pp. 5-12. doi:10.1016/j.infbeh.2015.11.006 Retrieved from https://www.ncbi.nlm.nih.gov/pubmed/26995647

Tracy, L. M., \& Giummarra, M. J. (2017). Sex differences in empathy for pain: What is the role of autonomic regulation? Psychophysiology, 54(10), pp. 1549-1558. doi:10.1111/psyp.12895 Retrieved from https://www.ncbi.nlm.nih.gov/pubmed/28555773

van de Mortel, T. F. (2008). Faking it: social desirability response bias in selfreport research. Australian Journal of Advanced Nursing, 25(4), pp. 40-48.

Wieck, C., \& Kunzmann, U. (2015). Age differences in empathy: Multidirectional and context-dependent. Psychology and Aging, 30(2), pp. 407-419. doi:10.1037/a0039001 Retrieved from https://www.ncbi.nlm.nih.gov/pubmed/25894486

Woodruff, C. C., Martin, T., \& Bilyk, N. (2011). Differences in self- and other-induced $\mathrm{Mu}$ suppression are correlated with empathic abilities. Brain Research, 1405, pp. 69-76. doi:10.1016/j.brainres.2011.05.046 Retrieved from https://www.ncbi.nlm.nih.gov/pubmed/21741034

Yang, C. Y., Decety, J., Lee, S., Chen, C., \& Cheng, Y. (2009). Gender differences in the mu rhythm during empathy for pain: an electroencephalographic study. Brain Research, 1251, pp. 176-184. doi:10.1016/j.brainres.2008.11.062 Retrieved from https://www.ncbi.nlm.nih.gov/pubmed/19083993

Ze, O., Thoma, P., \& Suchan, B. (2014). Cognitive and affective empathy in younger and older individuals. Aging \& Mental Health, 18(7), pp. 929-935. doi:10.1080/13607863.2014.899973 Retrieved from https://www.ncbi.nlm.nih.gov/pubmed/24827596 
Table 1. Between-group comparisons in demographic and clinical information $(\mathrm{N}=65)$

Table 1. Between-group comparisons in demographic and clinical information $(N=65)$

\begin{tabular}{|c|c|c|c|c|c|}
\hline & & Age & $\begin{array}{l}\text { Years of } \\
\text { scolarity }\end{array}$ & BDI-II & BAI \\
\hline Seniors & $\begin{array}{c}\text { Females }(n= \\
17)\end{array}$ & $61.69 \pm 3.77$ & $14.82 \pm 2.58$ & $3.24 \pm 2.54$ & $3.76 \pm 3.38$ \\
\hline \multirow[t]{2}{*}{ (55-75 у.о.) } & Males $(n=15)$ & $62.67 \pm 5.01$ & $14.13 \pm 2.20$ & $3.00 \pm 3.44$ & $4.20 \pm 4.20$ \\
\hline & Total $(n=32)$ & $62.15 \pm 4.35$ & $14.50 \pm 2.40$ & $3.12 \pm 2.95$ & $3.97 \pm 3.73$ \\
\hline \multirow{3}{*}{$\begin{array}{l}\text { Young adults } \\
\text { (18-35 y.o.) }\end{array}$} & $\begin{array}{c}\text { Females }(n= \\
14)\end{array}$ & $20.01 \pm 1.22$ & $14.21 \pm 1.59$ & $4.79 \pm 2.69$ & $6.64 \pm 3.61$ \\
\hline & Males $(n=19)$ & $20.04 \pm 1.66$ & $13.74 \pm 1.66$ & $2.79 \pm 2.02$ & $3.84 \pm 3.32$ \\
\hline & Total $(n=33)$ & $20.03 \pm 1.47$ & $13.94 \pm 1.62$ & $3.64 \pm 2.50$ & $5.03 \pm 3.67$ \\
\hline \multirow{3}{*}{$2 \times 2$ ANOVAs } & $\begin{array}{c}\text { GROUP } * \text { SEX } \\
F(1,61)=\end{array}$ & $\begin{array}{c}0.346 \\
(p=.559)\end{array}$ & $\begin{array}{c}0.04 \\
(p=.836)\end{array}$ & $\begin{array}{c}1.74 \\
(p=.193)\end{array}$ & $\begin{array}{c}3.21 \\
(p=.078)\end{array}$ \\
\hline & $\begin{array}{c}\text { GROUP } \\
F(1,61)=\end{array}$ & $\begin{array}{c}2684.07 \\
(p<.001)\end{array}$ & $\begin{array}{c}0.97 \\
(p=.330)\end{array}$ & $\begin{array}{c}1.005 \\
(p=.168)\end{array}$ & $\begin{array}{c}1.95 \\
(p=.320)\end{array}$ \\
\hline & $\begin{array}{c}\text { SEX } \\
F(1,61)=\end{array}$ & $\begin{array}{c}0.39 \\
(p=.535)\end{array}$ & $\begin{array}{c}1.30 \\
(p=.259)\end{array}$ & $\begin{array}{c}2.79 \\
(p=.195)\end{array}$ & $\begin{array}{c}1.72 \\
(p=.100)\end{array}$ \\
\hline
\end{tabular}

BDI-II = Beck Depression Inventory-II; BAI = Beck Anxiety Inventory;

Numbers are presentend as Mean \pm SD 
Table 2. Descriptive statistics of mu rhythm during the 500-1500 ms post-stimulus and QE scores

Table 2. Descriptive statistics of mu rhythm during the 500-1500 ms post-stimulus and QE scores

\begin{tabular}{cccccccccc}
\hline & \multicolumn{3}{c}{ Seniors } & \multicolumn{3}{c}{ Young adults } & \multicolumn{3}{c}{ Total } \\
\cline { 2 - 10 } & Females & Males & Total & Females & Males & Total \\
$(n=16)$ & $(n=15)$ & $(n=31)$ & $\begin{array}{c}\text { Females } \\
(n=13)\end{array}$ & $\begin{array}{c}\text { Males } \\
(n=19)\end{array}$ & $\begin{array}{c}\text { Total } \\
(n=32)\end{array}$ & $(n=29)$ & $(n=63)$ \\
\hline \multirow{2}{*}{ Joyful EFE } & 5.51 & 6.24 & 5.86 & 5.14 & 6.89 & 6.18 & 5.34 & 6.60 & 6.02 \\
& \pm 1.94 & \pm 1.65 & \pm 1.82 & \pm 1.59 & \pm 2.08 & \pm 2.06 & \pm 1.77 & \pm 1.90 & \pm 1.93 \\
Fearful EFE & 5.52 & 6.33 & 5.91 & 5.37 & 7.04 & 6.36 & 5.45 & 6.73 & 6.14 \\
& \pm 1.91 & \pm 1.83 & \pm 1.88 & \pm 1.40 & \pm 2.11 & \pm 2.01 & \pm 1.68 & \pm 2.00 & \pm 1.95 \\
Neutral EFE & 5.12 & 6.50 & 5.79 & 5.87 & 7.24 & 6.69 & 5.46 & 6.92 & 6.24 \\
& \pm 1.71 & \pm 1.79 & \pm 1.86 & \pm 1.97 & \pm 1.93 & \pm 2.03 & \pm 1.83 & \pm 1.88 & \pm 1.98 \\
QE & 40.52 & 34.73 & 37.81 & 42.79 & 42.16 & 42.42 & 41.55 & 38.88 & 40.15 \\
& \pm 9.73 & \pm 8.54 & \pm 9.51 & \pm 8.17 & \pm 9.25 & \pm 8.67 & \pm 8.17 & \pm 9.57 & \pm 9.32 \\
\hline
\end{tabular}

$\mathrm{EFE}$ = emotional facial expression; QE = Quotient of Empathy;

Numbers are presentend as Mean \pm SD 
Figure 1. Typical examples of an actor doing all three types of emotional facial expressions lasting $500 \mathrm{~ms}$.

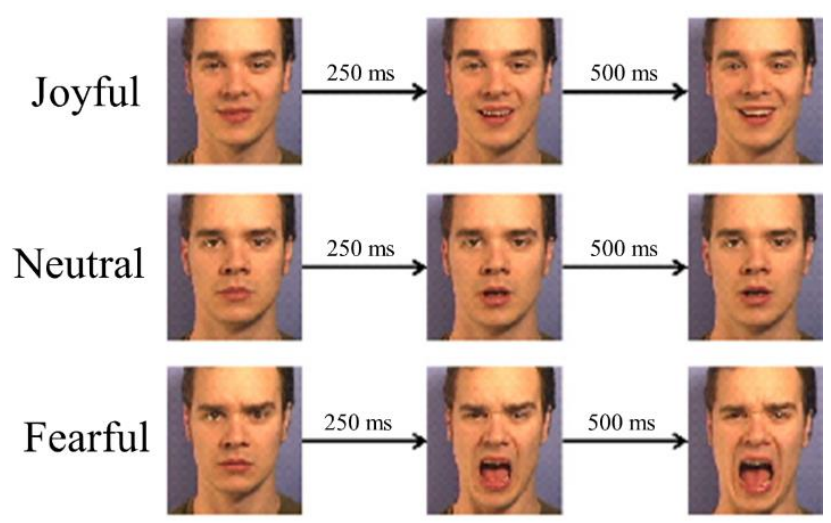


Figure 4. Baseline-corrected mu rhythm activity (8-13 Hz) between 500 and $1000 \mathrm{~ms}$ post-stimulus presentation in older and younger adults.

$*=p<0.05$. Error bars represent standard error of the means.

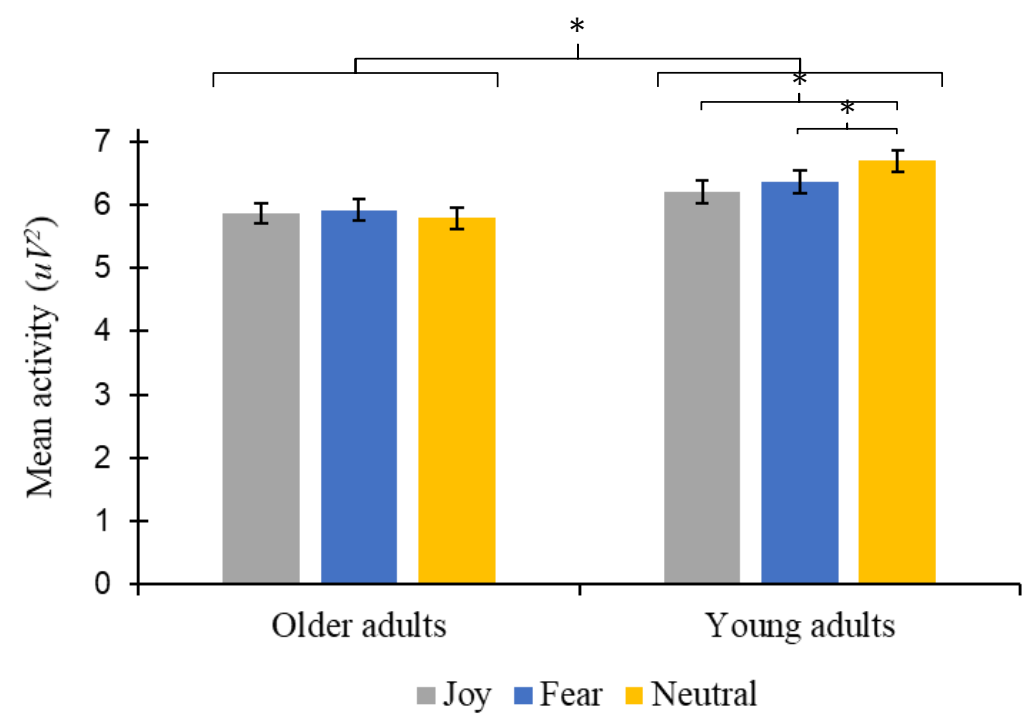


Figure 3. Baseline-corrected mu rhythm activity (8-13 Hz) between 500 and $1000 \mathrm{~ms}$ post-stimulus presentation in females and males.

$*=\mathrm{p}<0.05 . * *=\mathrm{p}<.01$. Error bars represent standard error of the means.

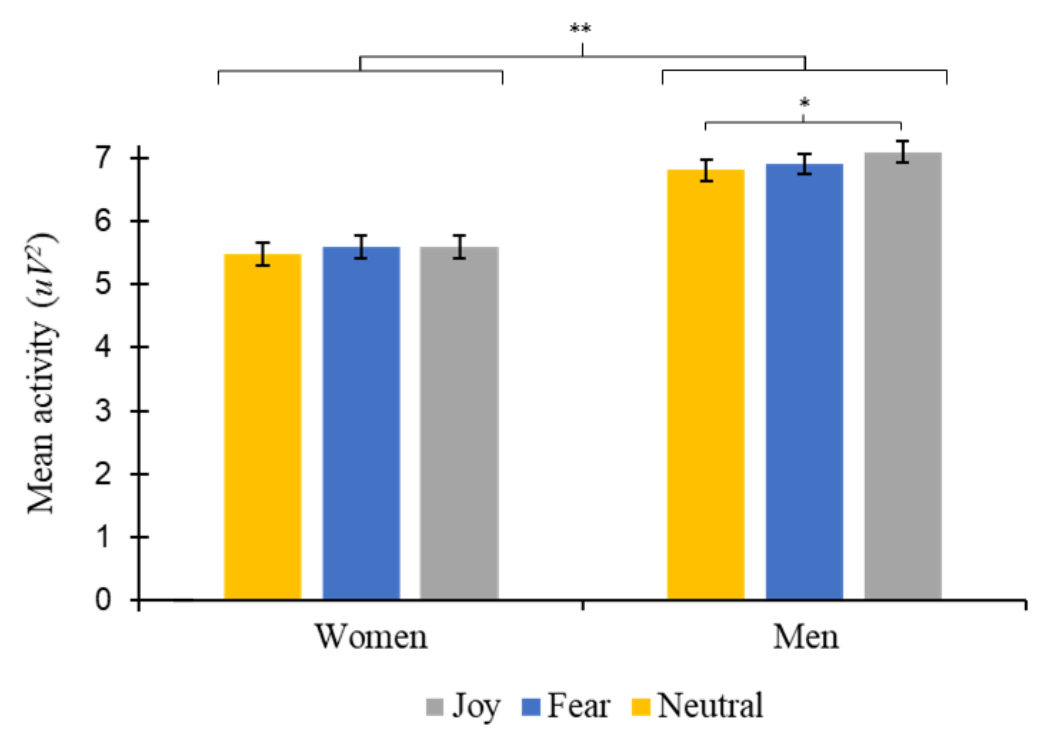

